\title{
marges Marges
}

revue d'art contemporain Revue d'art contemporain

\section{Gisèle Sapiro, Peut-on dissocier l'œuvre de l'auteur ?}

Paris, Seuil, 2020, 240 p.

\section{Nicolas Heimendinger}

\section{OpenEdition}

\section{Journals}

Édition électronique

URL : https://journals.openedition.org/marges/2603

DOI : $10.4000 /$ marges.2603

ISSN : 2416-8742

\section{Éditeur}

Presses universitaires de Vincennes

Édition imprimée

Date de publication : 20 mai 2021

Pagination : 166-167

ISBN : 978-2-37924-150-5

ISSN : $1767-7114$

\section{Référence électronique}

Nicolas Heimendinger, «Gisèle Sapiro, Peut-on dissocier l'œuvre de l'auteur ? », Marges [En ligne], 32 |

2021, mis en ligne le 20 mai 2021, consulté le 04 juin 2021. URL : http://journals.openedition.org/ marges/2603 ; DOI : https://doi.org/10.4000/marges.2603 


\section{Gisèle Sapiro, Peut-on dissocier l'œuvre de l'auteur?}

Paris, Seuil, 2020, 240 p.

En France comme à l'étranger, les cas se sont multipliés récemment de contestations mettant en cause la publicité et les distinctions accordées à certains artistes, historiques ou toujours actifs, dont la conduite ou les propos sont jugés condamnables. Hautement polémiques, ces débats ont pris un tour " confus, où le style pamphlétaire, qui privilégie l'amalgame et la mauvaise foi pour disqualifier l'adversaire, l'emporte souvent sur l'argumentation rationnelle.» (p. 10). C'est précisément à une analyse rationnelle des arguments employés au cours de ces débats que s'emploie Gisèle Sapiro dans cet essai. Elle s'appuie pour cela, non seulement sur son propre travail en matière de sociologie de la littérature et des intellectuels, mais aussi sur un large éventail de références théoriques, allant de la philosophie analytique d'Anscombe ou Kripke au concept de fonction-auteur chez Foucault. L'un des principaux intérêts de l'ouvrage réside dans son effort constant pour spécifier les différents problèmes et cas de figure relatifs à la morale de l'auteur, généralement ramenés à une même question récurrente, réductrice et sans nuance: faut-il, oui ou non, séparer l'œuvre de l'artiste? Ces amalgames, sans doute inévitables dans le débat public, mais aggravés par les modalités actuelles de l'expression médiatique, expliquent pour une part les dialogues de sourd auxquels se réduisent bien souvent ces controverses.
La première partie de l'essai, la plus théoricienne, distingue ainsi trois catégories de rapports entre l'œuvre et son auteur. La relation métonymique, tout d'abord, renvoie au nom d'auteur compris comme simple «étiquette ", comme opérateur verbal de rassemblement d'une «œuvre », dont on peut exclure (par conviction ou par opportunisme) certaines productions jugées extérieures au «projet créateur» qui lui donne sa cohérence (p. 29): les pamphlets antisémites de Wagner ou Céline peuvent être ainsi rejetés hors de l'œuvre artistique que désignent ces deux noms propres. La relation de ressemblance, quant à elle, conteste ce type de partage, en considérant l'œuvre (et donc toute publication) comme une expression de la personne de l'auteur. C'est ce qui justifie l'attribution aux écrivains de la responsabilité morale et pénale des textes qu'ils publient, avec toutes les ambiguïtés induites par la relation entre les convictions de l'auteur et le point de vue du narrateur, où il est parfois difficile, de Flaubert à Houellebecq, de faire la part de l'ironie et de l'identification. C'est ce qui permet aussi une analyse psychologique et sociologique des œuvres, renversant les effets de dépersonnalisation produits par l'élaboration fictionnelle ou théorique, à l'instar de Bourdieu décelant dans l'architecture conceptuelle de Heidegger l'empreinte des thèses de la révolution conservatrice allemande, indissociable de 
la trajectoire sociale du philosophe. Enfin, le rapport d'un auteur à son œuvre est aussi un rapport d'intentionnalité, dont l'interprétation a constitué le nœud de nombreuses critiques (et procès) adressées aux artistes, des poèmes décadents de Baudelaire aux paroles misogynes d'Orelsan, en passant par l'exposition antiraciste contestée de Brett Bailey, «Exhibit B »: jusqu'à quel point la représentation du «mal » peut être justifiée par l'intention de dénonciation affichée par son auteur?

Cette attention fine portée à la variété des cas est amplifiée dans la seconde partie de l'ouvrage où l'autrice distingue, en se fondant sur divers exemples, trois types d'« auteurs scandaleux » (p. 91). Le premier type, celui de «l'abus d'autorité » (p. 97), illustré par les affaires Matzneff et Polanski, comprend des auteurs qui ont mis à profit, pour commettre des actes condamnables, l'autorité charismatique et institutionnelle conférée par leur statut d'artistes reconnus, avec la circonstance aggravante dans le cas de Matzneff d'avoir explicitement construit son œuvre autour d'une apologie de la pédophilie, là où le dernier film de Polanski, sur un innocent accusé à tort (Dreyfus), ne constitue tout au plus qu'une défense indirecte et métaphorique du cinéaste. Sapiro se concentre ensuite sur différents intellectuels s'étant compromis avec le nazisme, en distinguant des auteurs ayant avoué et renié (parfois de manière ambiguë) leurs engagements de jeunesse (Grass, Blanchot, Jauss), des auteurs ne les ayant jamais publiquement regrettés (Heidegger, de Man) et des auteurs dont l'œuvre toute entière se confond avec l'engagement fasciste et antisémite (Maurras). La dernière sous-partie est dédiée à un cas singulier, celui de Peter Handke, dont Sapiro met en lumière les ambiguïtés du discours, non réductible pour autant au négationnisme qui a pu lui être reproché.

Ainsi, tout en constatant les excès possibles (souvent réactifs) de certaines accusations adressées aux artistes et intellectuels, Sapiro bat en brèche les entreprises de défense qui, par erreur ou par mauvaise foi, réduisent à une volonté de censure des critiques qui peuvent être fondées aussi bien moralement que légalement. En ce sens, ces polémiques témoignent, au contraire, de «la vitalité du débat démocratique » (p. 9). L'analyse morale se double en outre d'une réflexion herméneutique: un autre intérêt de l'ouvrage en effet est de montrer que la prise en compte du lien œuvre / auteur, sans constituer pour autant une clef d'interprétation exclusive, peut nourrir des lectures renouvelées, comme l'illustre le cas de Heidegger. La reconnaissance d'une "autonomie relative» de l'art, de la littérature ou de la philosophie, que défend en conclusion l'autrice, fondée sur la sociologie des champs de Bourdieu, s'oppose aux tendances réductrices qui ont traditionnellement représenté (et continuent de faire peser) une menace sur la liberté des artistes et des intellectuels. Elle se distingue aussi, réciproquement, d'une conception esthète trop absolue et quelque peu datée, se réclamant souvent de références mal comprises (comme le Contre Sainte-Beuve de Proust) : la défense d'une séparation totale de l'œuvre et de l'auteur, non seulement apparaît intenable sur le plan de l'interprétation des œuvres, mais sert souvent de paravent pour préserver l'impunité d'actes ou de propos qu'aucune sublimation artistique ni théorique ne saurait absoudre - ce que les mobilisations et les critiques croissantes ces dernières années ont le mérite d'avoir mis en lumière.

\section{Nicolas Heimendinger}

